\title{
Parents' Education and Child Schooling Outcome: Evidence from Uganda
}

\author{
Edward Bbaale $^{1} \&$ Faisal Buyinza ${ }^{1}$ \\ ${ }^{1}$ School of Economics, Makerere University, Uganda \\ Correspondence: Faisal Buyinza, School of Economics, Makerere University, Uganda. E-mail: \\ ebbaale@fema.mak.ac.ug or fbuyinza@fema.mak.ac.ug
}

Received: July 31, 2013 Accepted: August 27, 2013 Online Published: November 29, 2013

doi:10.5539/jpl.v6n4p77 URL: http://dx.doi.org/10.5539/jpl.v6n4p77

\begin{abstract}
This paper presents an analysis of the determinants of school enrolment and attainment rates in Uganda from a gender perspective. We used the DHS 2006 data set and employed maximum likelihood binary and ordered probit models in our estimation. Whereas improvements in parents' education promote the schooling outcome of both boys and girls, it is not without inclination. Fathers' education significantly favors boys' schooling and mothers' education significantly favors girls' schooling. This suggests that there are differences in parents' preferences for schooling of children. We also find that the higher the parents' education (secondary and postsecondary levels) the more favorable are the child's schooling outcomes. For more favorable child schooling outcomes for future generations, government should strengthen policies aimed at educating boys and girls beyond secondary level. The government universal secondary education program is a good start and needs to be strengthened.
\end{abstract}

Keywords: parents education, school enrolment, education attainment, gender, Uganda

\section{Introduction}

The role of education in the attainment of favourable social outcomes such as lower mortality rates (maternal, infant, and child), favourable nutrition outcomes, and increased child schooling cannot be underscored. The ability of a country to provide quality education to the entire population and children in particular, has always been a matter of great policy concern. Therefore, countries the world over take deliberate and purposeful efforts to enhance child schooling outcomes. The government of Uganda has already made progress into some of the targets set in the Millennium Development Goals (United Nations, 2000) and in the National Development Plan (2010/11-2014/15). For example, the government has since January 1997 implemented UPE as one of its main policy tools for poverty reduction and human development. Ten years later, in 2007 the government implemented the Universal Secondary Education (USE). This was after a realization that many pupils dropped out after primary seven due to lack of tuition fees for secondary school enrolment (Republic of Uganda, 2008). In spite of these commendable efforts, hitherto, there was no empirical investigation into the factors determining school enrolment and attainment rates. In the absence of in-depth studies on the determinants of the demand for schooling, policy formulation and advocacy may lack empirical relevancy. Additionally, owing to the usually high private and social returns to education, it remains paradoxical that school attainment rates are still very low in Uganda ( $16 \%$ for primary, $4 \%$ for secondary and only $0.7 \%$ for post-secondary (Note 1$)$ ).

It is worth noting that the Uganda Demographic and Health Survey Report elaborates on the factors influencing child schooling outcomes in Uganda. These factors are broadly grouped as demographic, cultural, household environment, and socio-economic factors, size of household, ethnicity, place of residence, and religious background, among others (Uganda Bureau of Statistics and Macro International, 2007). However, it is noteworthy that the UDHS undertakes only a descriptive analysis of the underlying factors and does not render a rigorous empirical analysis. While descriptive analysis may provide insights into the key factors of interest, it falls short of attaching a statistical significance on the identified factors. In addition, the DHS report did not pay close attention to the distinction of the factors which influence current school enrolment and those influencing school attainment rates. The report ended up mapping current factors like household wealth on school attainment, yet such events were non-existent when the schooling decision was being made. Also the cohorts of children that actually completed a certain level couldn't be correctly identified in the report and hence the biases emerging due to censoring could not be avoided. 
Over the years, literature creating a link between parents' schooling and schooling outcomes of children has substantially grown (Behrman et al., 1984; Schultz, 1988; Parish et al., 1993; Strauss et al., 1995; Lam et al., 1999; Glick et al., 2000; Glewwe et al., 2001; Alderman et al., 2000; Brown et al., 2002; Orazem et al., 2008; Sackey et al., 2007; Mani et al., 2009). These authors find that parents' schooling is positively associated with favorable child schooling outcomes. While parents' education effect unquestionably exists, literature presents no consensus on the nature of relationship and on the level of parents' schooling that may have a significant impact. Some authors find that mother's schooling is more important than father's schooling (Schultz, 1993; Birdsall, 1985). Others find that mother's and father's schooling effect on child schooling attainment does not significantly differ from each other (King et al., 1988; Behrman et al., 1987). Yet others like Glick et al. (2000) find that mothers' and fathers' schooling is inclined towards girls' and boys' attainment rates, respectively. On the other hand, it is frequently argued in the literature that parents' education is mainly a conduit for socioeconomic improvement and determining the region and location of individuals. That its effect on child quality outcomes shrinks after controlling for these factors (Desai et al., 1998; Frosta et al., 2005). The debate concerning this issue is progressing and therefore a deeper understanding into these relationships is called for.

This paper provides answers to the following pertinent questions: First, controlling for other socio-economic characteristics, does the level of education acquired by parents affect education enrolment and attainment of their children? If so, what level of a parents' schooling has a significant impact on child schooling outcomes? This implies that understanding the impact of parents' education per se on child schooling attainment is not enough, the differential impact of various education levels can provide more meaningful insights. Second, is parents' schooling equally important for boys' and girls' schooling outcomes? We hypothesize that parents' education positively influences child schooling enrolment and attainment rates. Additionally, there exist differences in the parents' preferences for schooling of boys and girls.

The reminder of the paper is structured as follows. Section 2 gives the theoretical framework and the estimation strategy. Section 3 presents a discussion of the main findings, while Section 4 concludes the paper and highlights the paper's implications for policy.

\section{Theoretical Framework and Methodology}

The demand for education, just like in the body of literature that concentrated on the demand for health by the household, is also analyzed within the theory of consumer behavior. Household makes a choice between the schooling good and other goods demanded by the household under the budget, schooling production, and time constraints. This type of theoretical exposition has been observed in several papers dating back three decades or so (King et al., 1988; Becker, 1991; Mani et al., 2009). The utility function that a household may seek to maximize contains several goods; schooling outcome of children $\left(s_{c}\right)$, food consumption $(f)$, non-food consumption such as medical inputs $(g)$, leisure $(l)$ and taste $(t)$. Thus, the one period utility function of the household takes the following form:

$$
U=U\left[s_{c}, f, g, l, t\right]
$$

Standard economic theory predicts the presence of schooling production function of the household that imposes a constraint on its utility maximization. This production function relates schooling attainment to various schooling inputs. Schooling inputs include market purchased inputs such as tuition fees, books, uniforms, and other scholastic materials denoted by $(x)$, time of the mother $\left(t_{m}\right)$ and father $\left(t_{f}\right)$ in producing child schooling outcome, education of the mother $\left(e_{m}\right)$ and father $\left(e_{f}\right)$. It also includes the quality of the household environment $\left(\mu_{H E N V}\right)$ which can be represented by such variables as source of water, electricity, type of housing facility, type of floor, and the community services such as availability of schools and other infrastructure that affect schooling attainment. Additionally, the function may include the social environment factors $\left(\mu_{\text {SENV }}\right)$ including residence, region, and religion, parents' demographic characteristics $\left(p_{d}\right)$ (such as age cohorts), and child's characteristics $\left(p_{c}\right)$ (age and gender) as well as the innate child abilities $(\omega)$.

Thus;

$$
s_{c}=s_{c}\left(x, t_{m}, t_{f}, e_{m}, e_{f}, \mu_{H E N V}, \mu_{S E N V}, p_{d}, p_{c}, \omega\right)
$$

The theory of household production models underscores the mutual exclusiveness of activities requiring the time participation of the mother and the father. These activities include; farm production or time allocated for paid work, 
production of child health and schooling attainment, and leisure time among others. It is prudent therefore to include a time constraint of the mother and the father. Parents participate fully in the time intensive schooling activities of their children; e.g., they assist them to do daily homework and also some parents drop and pick children from school. The total time allocation of the parents is given by the following expression:

$$
\begin{aligned}
& t_{m}=l_{m}+w_{m}+c_{m} \\
& t_{f}=l_{f}+w_{f}+c_{f}
\end{aligned}
$$

From Equation 3, $t_{m}, l_{m}, w_{m}$ and $c_{m}$ is total time available to the mother, distributed to leisure, work, and producing child schooling outcome, respectively. $t_{f}, l_{f}, w_{f}$ and $c_{f}$ is total time available to the father, distributed to leisure, work, and producing child schooling outcome respectively.

Standard microeconomic theory predicts that the household's attainable and unattainable combinations of good are mapped by a budget constraint. The household's budget constraint appears as:

$$
P_{x} x+P_{f} f+P_{g} g+P_{l} l=h_{m} w_{m}+h_{f} w_{f}+\eta
$$

From Equation 4, $P_{x} x, P_{f} f, P_{g} g, P_{l} l, h_{m}, w_{m}, h_{f}, w_{f}$ and $\eta$ refer to the cost of schooling inputs such as books and school fees; cost of food consumption, cost of non-food consumption such as medication, cost of the leisure good, labor income of the mother, labor income of the father, and the exogenous non-labor income.

From this structural model, using optimization techniques, we can derive the demand for child schooling by a typical household given by the following expression.

$$
s_{c}=s_{c}\left(e_{m}, e_{f}, \mu_{H E N V}, \mu_{S E N V}, p_{x}, p_{f}, p_{g}, p_{d}, p_{c}, \omega\right)
$$

From Equation 5, $s_{c}, e_{m}, \mu_{H E N V} \mu_{S E N V} p_{x}, P_{x} x, \mu_{S E N V} p_{f}, p_{g}, p_{d}, p_{c}$ and $\omega$ is child education outcomes mother's level of education, father's level of education, household environment, social environment, price of schooling inputs, price of food, price of non-food items like medicine, parents' demographic characteristics like age, child's characteristics including age and gender as well as the innate child abilities. School enrollment is a dummy variable equal to one if a child was currently enrolled in school at the time of the survey, and zero otherwise. Schooling attainment measure is constructed by restricting our sample to include observations on children with completed schooling spells alone. With this we can estimate attaining a specific level of education for a particular child. These two definitions of the dependent variable are in current terms and so allow us to use current socio-economic characteristics to explain the variations in enrollment and relative grade attainment.

Following Sackey (2007) we estimate the current enrollment status by using the probit model indicating whether or not a child of school going age has enrolled in school. The probit model estimated takes the following form:

$$
\begin{gathered}
E_{i}^{*}=X_{i} \beta+\mu_{i}, \quad \forall i=1, \ldots, n \\
E_{i}=\left\{\begin{array}{l}
1: \text { if } E_{i}^{*}>0 \\
0: \text { if otherwise }
\end{array}\right.
\end{gathered}
$$

From Equation 7, $E_{i}$ is a binary variable equal to 1 if the $i^{\text {th }}$ child was currently enrolled in school, and zero otherwise. This response is determined by the latent variable $E_{i}^{*} . X_{i}$ is a vector of explanatory variables, $\beta$ is a vector of parameters to be estimated and $\mu_{i}$ is the error term which is assumed to be normally distributed.

On the other hand, we estimate the current schooling attainment of children by using an ordered probit model. As mentioned before, we restrict our sample to include observations on children with completed schooling grades in order to obtain unbiased and consistent parameter estimates. To write a mathematical exposition of the ordered probit model, we need the ordered categories of the highest education level attained by the child. For the purposes of this paper and in line with Uganda's education system, they include; 1 = no education; 2 = primary school; $3=$ secondary school; and 4 = post-secondary school. The ordered probit model estimated takes the following form: 


$$
A_{i}^{*}=X_{i} \alpha+\eta_{i} \forall i=1, \ldots, n
$$

From Equation $8, A_{i}^{*}$ is a latent unobserved variable and represents the respondent's actual underlying education attainment, $X_{i}$ is a vector of explanatory variables, $\alpha$ is a vector of parameters to be estimated and $\eta_{i}$ is the error term which is assumed to be normally distributed. Following Sackey (2007) and Bruce et al. (2004) the observed child schooling attainment variable $A_{i}$ is specified as follows:

$$
\begin{aligned}
& A_{i}=1(\text { no schooling }), \text { if } A_{i}^{*}<\mu_{1} \\
& A_{i}=2(\text { primary }), \text { if } \mu_{1}<A_{i}^{*}<\mu_{2} \\
& A_{i}=3(\sec \text { ondary }), \text { if } \mu_{2}<A_{i}^{*}<\mu_{3} \\
& A_{i}=4(\text { post }-\sec \text { ondary }), \text { if } \mu_{3}<A_{i}^{*}<\mu_{4}
\end{aligned}
$$

The $\mu$ 's are threshold parameters or cut-points to be estimated together with the vector of unknowns $(\alpha)$.

\subsection{Data Sources and Sample Randomness Issues}

The data was obtained from the Uganda Demographic and Health Survey (UDHS) 2006 conducted by Macro International on behalf of the Uganda Bureau of Statistics (UBOS). The 2006 (UDHS) is a nationally representative survey of 8,531 women age 15-49 and 2,503 men age 15-54. UBOS 2006 UDHS survey contains a rich source of information on household size, age and sex distribution, religious affiliation, occupation of household members, the number of children ever born by a woman, reproductive health, marital status, wealth index, maternal health care utilization, and knowledge of health issues. The data set contains information on schooling attainment and other characteristics on all children ever born in a family, not only on children living at home during the survey.

\section{Presentation and Discussion of the Findings}

In this section we present the quantitative results of the analysis of parents' education and child school enrolment and attainment outcomes. In subsection 3.1.1 and 3.1.2 we present the results pertaining to child school enrolment and attainment outcomes respectively. School enrolment outcome is defined as children who were currently enrolled at the time of the survey and so we include the contemporaneous factors in the model. Yet, school attainment is not contemporaneous; it depends on such factors that were in place when the schooling decision was being made. We therefore eliminate contemporaneous factors such as household wealth status to avoid mapping current factors on to previous decisions. The likelihood ratio chi-square test result shows that our models are robust.

\subsection{School Enrolment}

It is worth noting that the school enrolment rate is quite low in Uganda, on average, it stands at $35 \%$ for the entire sample, $38 \%$ for boys, and $32 \%$ for girls (Table 1 ).

Parents' schooling represents fascinating differences in the school enrolment rates. Highly educated parents are associated with high child school enrolment rates. Mothers with post-secondary education are associated with $36 \%$ of children enrolling into school compared to $32 \%$ belonging to their counterparts with no education at all. The scenario is not different for boys and girls. Considering fathers' schooling, the data reveal pretty much the same picture as for mother's schooling. In spite of this, mothers' and fathers' education appear to be inclined towards girls' and boys' school enrolment, respectively (Table 1). This difference is very important for policy especially if the government is interested in targeting a particular group of children as a long-term goal human capital development is concerned.

As expected, the wealth status of the household in Uganda is associated with spectacular differences in the child school enrolment rates. Households in the richest quintile are associated with $38 \%$ of children enrolling into school compared to only $28 \%$ associated with their counterparts in the poorest wealth quintile. This wealth effect on school enrolment is observed to be more prominent for girls than for boys (Table 1). Implying the wealthier a household becomes, the higher the number of girls that are enrolled into school. Therefore, the government poverty reduction programs designed to achieve MDG 1 are very essential in this area. Enrollment differences between the regions sampled were minor. However, the central region leads all regions with overall enrollment at 37 percent, boys accounting for 40 percent and girls 35 percent. The differences across regions average no more than 1 percent. 
Table 1 . School Enrolment by children 5-20 years, by mean percentages

\begin{tabular}{|c|c|c|c|}
\hline Category & Enrolment (Full sample) & Enrolment (Boys) & Enrolment (Girls) \\
\hline Female education: No education & 32 & 37 & 28 \\
\hline Primary & 36 & 39 & 33 \\
\hline Secondary & 37 & 40 & 36 \\
\hline Post-secondary & 36 & 38 & 34 \\
\hline Partner's education: No education & 27 & 31 & 24 \\
\hline Primary & 35 & 37 & 33 \\
\hline Secondary & 35 & 39 & 32 \\
\hline Post-secondary & 39 & 42 & 36 \\
\hline Wealth Quintile: Poorest & 28 & 32 & 25 \\
\hline Poorer & 32 & 35 & 29 \\
\hline Middle & 36 & 40 & 33 \\
\hline Richer & 39 & 42 & 36 \\
\hline Richest & 38 & 41 & 37 \\
\hline Region: Central & 37 & 40 & 34 \\
\hline East & 37 & 39 & 35 \\
\hline North & 31 & 36 & 27 \\
\hline West & 34 & 37 & 32 \\
\hline Household head: Female & 40 & 50 & 33 \\
\hline Not female head & 32 & 32 & 32 \\
\hline Religion: Catholic & 33 & 37 & 30 \\
\hline Protestant & 36 & 39 & 33 \\
\hline Muslim & 38 & 40 & 36 \\
\hline Other & 35 & 38 & 33 \\
\hline Father's Occupation: Professional & 42 & 47 & 38 \\
\hline Agriculture & 33 & 36 & 30 \\
\hline Services + Sales & 37 & 40 & 35 \\
\hline Manual Skilled + unskilled & 32 & 34 & 31 \\
\hline Number of children: 1 & 22 & 24 & 22 \\
\hline 2 & 20 & 21 & 20 \\
\hline 3 & 27 & 28 & 26 \\
\hline 4 & 32 & 36 & 29 \\
\hline $5+$ & 41 & 45 & 38 \\
\hline Total & 35 & 38 & 32 \\
\hline $\mathrm{N}$ & 15,000 & 7,675 & 7,325 \\
\hline
\end{tabular}

Source: Authors' own analysis using the Uganda Demographic and Health Survey 2006

The data reveal that female headed households are associated with a higher enrolment rate of $40 \%$ for the entire sample, $50 \%$ for boys, and 33\% for girls compared to only 32\% across all subsamples associated with their counterparts in other households. This may be attributed to the importance of the independence of women in taking key decisions especially in favor of child quality. Different enrolment rates can also be observed across religious groups. Unexpectedly, the Muslims lead all other religions with an enrolment rate of $38 \%$ for the full sample, $40 \%$ 
for boys, and $36 \%$ for girls. They are followed by the Protestants (36\%), then others $(35 \%)$ (Including evangelicals), and the Catholics (33\%) come last. Whereas there may not be a direct policy implication, the government may encourage religious leaders, as part of their mandate, to campaign for greater child school enrolment given UPE and USE.

In regard to fathers' occupation, the study reveals interesting differences in the child enrolment rates. Fathers that are professionals are associated with the highest child enrolment rates for all the subsamples; with 42 percent for the full sample, 47 percent for boys, and 38 percent for girls. They are followed by fathers in services/sales, agriculture manual, skilled plus unskilled in that order. These findings are as expected and may be linked to education which is obviously uppermost amongst professionals who are also more likely to be in the highest wealth quintile making school enrolment amongst their children easier. Further, it is surprising to note that the higher the number of children in a family, the higher the enrolment rates. For the full sample, school enrolment rate is $41 \%$ for those with at least five children, compared to only $22 \%$ for those with only one child. The same picture is observed for the subsamples of boys and girls, though the effect is stronger for boys than for girls (Table 1).

Table 2 shows marginal effects from the probit estimation of current school enrolment and parents' schooling together with other socioeconomic factors. Our results reveal that parents' schooling increases the probability of child school enrolment. Mother's schooling at all levels; compared to their counterparts with no education, increases the probability of child enrolment by 2-5 percent and the coefficients are significant at five percent level. However, father's education, compared to those with no education, appears to be stronger with a probability of 8-9 percent and the coefficients are significant at one percent level. Considering the subsamples of boys and girls, there are interesting differences. The effect of mothers' schooling on enrolment declines for the subsample of boys and increase for the subsample of girls. However, fathers' schooling is revealed to be imperative for the enrolment of both boys and girls. Fathers' schooling at all levels; compared to counterparts with no education, increases the probability of boys' school enrolment by 10-12 percent and this effect is significant at one percent level. However, fathers' schooling at all levels increases the probability of girls' school enrolment by 5-8 percent compared to their counterparts with no education at all. It is clear that the effect of fathers' schooling on boys' enrolment outweighs that on girls' enrolment, an issue pointing to the existence of child discrimination by gender on schooling opportunities. Mothers' schooling at primary and secondary levels, compared to their counterparts with no education, increases the probability of girls' school enrolment by 3-4 percent. These quantitative findings are supported by descriptive findings in Table 1 .

Table 2. Determinants of School Enrolment 5-24 years (Probit analysis: Marginal effects)

\begin{tabular}{lccc}
\hline \multirow{2}{*}{ Variable } & Model $(1)$ & Model $(2)$ & Model $(3)$ \\
\cline { 2 - 4 } & Full sample & Boys & Girls \\
\hline Female Education: Primary & $0.0222(2.38)^{* *}$ & $0.0106(0.75)$ & $0.0338(2.70)^{* * *}$ \\
Secondary & $0.03010(2.04)^{* *}$ & $0.0222(0.97)$ & $0.0408(2.00)^{* *}$ \\
Post-secondary & $0.0526(2.02)^{* *}$ & $0.0552(1.41)$ & $0.0477(1.37)$ \\
Partner's: Primary & $0.0871(6.97)^{* * *}$ & $0.0985(5.32)^{* * *}$ & $0.0762(4.49)^{* * *}$ \\
Secondary & $0.0809(5.25)^{* * *}$ & $0.1214(5.22)^{* * *}$ & $0.0484(2.36)^{* *}$ \\
Post-secondary & $0.0895(3.93)^{* * *}$ & $0.0990(2.88)^{* * *}$ & $0.0762(2.51)^{* *}$ \\
Region: East & $0.0152(1.30)$ & $0.0161(0.91)$ & $0.0163(1.04)$ \\
North & $0.0101(0.77)$ & $0.0221(1.13)$ & $-0.0029(0.16)$ \\
West & $0.0045(0.39)$ & $0.0109(0.62)$ & $0.0014(0.09)$ \\
Urban & $-0.0232(1.76)^{*}$ & $-0.0176(0.87)$ & $-0.02318(1.34)$ \\
Female head & $0.0837(10.73)^{* * *}$ & $0.1711(14.10)^{* * *}$ & $0.0244(2.40)^{* *}$ \\
Religion: Protestant & $0.0144(1.66)^{*}$ & $0.0120(0.92)$ & $0.0141(1.21)$ \\
Muslim & $0.0286(2.34)^{* *}$ & $0.03174(1.72)^{*}$ & $0.0252(1.54)$ \\
Other & $0.0096(0.76)$ & $0.0087(0.45)$ & $0.0105(0.62)$ \\
Wealth index: poorer & $0.0370(2.79)^{* * *}$ & $0.0536(2.69)^{* * *}$ & $0.0230(1.30)$
\end{tabular}




\begin{tabular}{|c|c|c|c|}
\hline Middle & $0.0755(5.23)^{* * *}$ & $0.0981(4.53)^{* * *}$ & $0.0540(2.81)^{* * *}$ \\
\hline Richer & $0.1009(6.76)^{* * *}$ & $0.1192(5.32)^{* * *}$ & $0.0844(4.22)^{* * *}$ \\
\hline Richest & $0.134(7.34)^{* * *}$ & $0.1415(5.18)^{* * *}$ & $0.1228(5.00)^{* * *}$ \\
\hline $\begin{array}{l}\text { Father's } \\
\text { Agriculture }\end{array}$ & $-0.0364(2.36)^{* *}$ & $-0.0435(1.83)^{*}$ & $-0.0387(1.91)^{*}$ \\
\hline Services + sales & $-0.0267(1.67)^{*}$ & $-0.0506(2.03)^{* *}$ & $-0.0122(0.58)$ \\
\hline Manual Skilled + unskilled & $-0.0460(2.96)^{* * *}$ & $-0.0738(3.08)^{* * *}$ & $-0.0304(1.49)$ \\
\hline Water source: Borehole & $0.0007(0.05)$ & $0.0060(0.30)$ & $-0.0010(0.06)$ \\
\hline Protected well & $-0.0098(0.70)$ & $-0.0167(0.78)$ & $-0.0010(0.05)$ \\
\hline Unprotected well & $-0.0261(1.91)^{*}$ & $-0.01753(0.84)$ & $-0.0298(1.65)^{*}$ \\
\hline Number of children: 2 & $-0.0003(0.01)$ & $0.0072(0.22)$ & $-0.0038(0.15)$ \\
\hline 3 & $0.0990(4.89)^{* * *}$ & $0.1064(3.41)^{* * *}$ & $0.0920(3.49)^{* * *}$ \\
\hline 4 & $0.1588(7.86)^{* * *}$ & $0.211(6.76)^{* * *}$ & $0.1142(4.34)^{* * *}$ \\
\hline $5+$ & $0.2400(15.15)^{* * *}$ & $0.2759(11.21)^{* * *}$ & $0.2088(10.05)^{* * *}$ \\
\hline Toilet type: Pit no slab & $-0.0018(0.10)$ & $-0.0306(1.03)$ & $0.0150(0.59)$ \\
\hline Pit with slab & $-0.0214(1.16)$ & $-0.0433(1.50)$ & $-0.0079(0.33)$ \\
\hline Bush + Composting & $-0.0824(3.83)^{* * *}$ & $-0.1081(3.27)^{* * *}$ & $-0.0643(2.26)^{* *}$ \\
\hline $\mathrm{N}$ & 17761 & 8203 & 9558 \\
\hline Pseudo R-square & 0.0518 & 0.0721 & 0.0443 \\
\hline Log-likelihood & -10783.683 & -5009.112 & -5681.6302 \\
\hline
\end{tabular}

Absolute value of $\mathrm{z}$ statistics in parentheses; * significant at $10 \% ;{ }^{* *}$ significant at $5 \%$; *** significant at $1 \%$

Our findings find support in the previous literature (Glick et al., 2000; Brown et al., 2002; Sackey et al., 2007; Mani et al., 2009 and Lam et al., 1999). In spite of the differences in the effect of schooling for the mother and the father, the key message rendered by our findings is clear. The higher the level of the parents' schooling the more favorable are child enrolment outcomes. Therefore, government effort to extend free education at primary and secondary levels is a good start and needs to be propelled to higher levels.

In addition to parents' schooling, our findings reveal the importance of other factors influencing child school enrolment outcomes. These include independence of women in taking key household decisions (proxied by female headed households), religious affiliation, and wealth status of the household, father's occupation, fertility choice of the household, household and social environment. These factors are statistically significant at one percent level and are also supported by the descriptive findings in Table 1 .

\subsection{School Attainment}

It is noteworthy that school attainment rates are quite low in Uganda especially at higher education levels. It is rather astonishing to note that the attainment rates of girls are higher than that of boys at all levels of education. On average, primary school attainment rate is $16 \%$ for the full sample, 19 percent for boys, and 22 percent for girls. At secondary and post-secondary levels of education, minor differences can be observed. The secondary school attainment rate is, on average 4 percent for both the full sample and boys, and 5 percent for girls. For post-secondary, it is 0.7 percent for the full sample, 0.8 percent for boys, and 1 percent for girls (Table 3 ). The prominence of girls may be attributed to the recent government effort targeting the girl child. For example, the government has since 1990 requested Makerere University to add an extra 1.5 points to all girls that apply for admission in order to increase the number of girls attaining university education. Donors have also established a number of scholarships targeting female students. For example, the Carnegie Corporation has since 2001 sponsored girls for University education at Makerere University particularly those from disadvantaged backgrounds (Note 2). These, and other similar efforts, may account for the observed school attainment rates in favor of girls. 
Table 3. School Attainment by children 13-30 years, by mean percentages

\begin{tabular}{|c|c|c|c|c|c|c|c|c|c|}
\hline \multirow[b]{2}{*}{ Variables } & \multicolumn{3}{|c|}{ Primary } & \multicolumn{3}{|c|}{ Secondary } & \multicolumn{3}{|c|}{ Post-secondary } \\
\hline & $\begin{array}{c}\text { Full } \\
\text { sample }\end{array}$ & Boys & Girls & $\begin{array}{c}\text { Full } \\
\text { sample }\end{array}$ & Boys & Girls & $\begin{array}{c}\text { Full } \\
\text { sample }\end{array}$ & Boys & Girls \\
\hline Female education: No education & 15 & 20 & 14 & 1 & 1.4 & 1 & 0.1 & 0.3 & 0 \\
\hline Primary & 20 & 19 & 29 & 2 & 4 & 1.2 & 0.2 & 0.4 & 0.1 \\
\hline Secondary & 10 & 15 & 12 & 14 & 11 & 23 & 1 & 2.2 & 0.6 \\
\hline Post-secondary & 7 & 8 & 9 & 5 & 7 & 6 & 11 & 5.4 & 18 \\
\hline Partner's education: No education & 14 & 15 & 17 & 0.8 & 1 & 1 & 0.02 & 0.05 & 0 \\
\hline Primary & 20 & 22 & 24 & 2 & 2 & 2.3 & 0.1 & 0.2 & 0.1 \\
\hline Secondary & 16 & 14 & 22 & 8 & 12 & 8 & 0.6 & 0.4 & 0.7 \\
\hline Post-secondary & 13 & 11 & 16 & 6 & 5 & 8 & 6 & 7 & 6 \\
\hline Region: Central & 19 & 17 & 20 & 7 & 6 & 8 & 2 & 1.4 & 2 \\
\hline East & 19 & 17 & 21 & 4 & 4 & 4 & 0.7 & 1 & 0.5 \\
\hline North & 20 & 18 & 21 & 3 & 3 & 2 & 0.3 & 0.5 & 0.01 \\
\hline West & 23 & 22 & 24 & 3 & 3 & 3 & 0.7 & 0.5 & 0.8 \\
\hline Location: Urban & 18 & 15 & 20 & 11 & 10 & 13 & 3 & 3 & 3 \\
\hline Rural & 21 & 19 & 22 & 3 & 3 & 3 & 0.5 & 0.5 & 0.5 \\
\hline Number of children: 1 & 19 & 21 & 29 & 8 & 10 & 12 & 2.4 & 3 & 4 \\
\hline 2 & 20 & 20 & 27 & 7 & 7 & 10 & 1.3 & 1.4 & 2 \\
\hline 3 & 17 & 18 & 22 & 5 & 5 & 7 & 0.8 & 1 & 1 \\
\hline 4 & 17 & 14 & 24 & 3 & 4 & 3 & 0.5 & 0.6 & 0.4 \\
\hline $5+$ & 17 & 19 & 19 & 2 & 2 & 1.5 & 0.2 & 0.3 & 0.09 \\
\hline Total & 16 & 19 & 22 & 4 & 4 & 5 & 0.7 & 0.8 & 1 \\
\hline $\mathrm{N}$ & 9163 & 4275 & 4888 & 1889 & 1042 & 847 & 420 & 234 & 186 \\
\hline
\end{tabular}

Source: Authors' own analysis using the Uganda Demographic and Health Survey 2006

The findings further reveal that parents' schooling positively associated with child school attainment rates at higher levels of child education (postsecondary) than at lower levels (primary and secondary). However, this is not to suggest that child school attainment rates are highest at higher levels of education. Mothers with post-secondary education are associated with a child post-secondary attainment rate of $11 \%$ compared to only $0.1 \%$ associated with their counterparts with no education at all. The same scenario can be observed for the subsamples of boys and girls but mothers' education effect is more strongly associated with attainment rate for girls than for boys. Mothers with post-secondary education are associated with a postsecondary school attainment rate for girls of $18 \%$ compared to only 5.4\% for boys (Table 3). However, at lower levels of child schooling (primary and secondary), mother's schooling is not clearly associated with higher child school attainment rates. At the primary level of child schooling, attainment rates rise with mothers' education up to primary level after which it is observed to decline. For the secondary level of child schooling, attainment rates rise with mothers education up to secondary level after which it is observed to decline. At the postsecondary level schooling whose attainment rates are positively associated with mothers' education. Our descriptive findings show that mothers' education and child attainment rates matches very well with that of fathers' schooling (Table 3). Both emphasize the role of higher parents' schooling in leading to higher child quality outcomes, particularly education attainment.

Our findings also reveal interesting regional differences in child school attainment rates at different levels of education (Table 3) in Uganda. The central region leads all other regions in the secondary and postsecondary school attainment rates and it lags in the primary school attainment rates. The central region is associated with an overall secondary school attainment rate of 7 percent, 6 percent for boys, and 8 percent for girls. It is followed by the eastern region with an overall secondary school attainment rate of 4 percent and this is the same for the 
subsamples of boys and girls. The northern (3\% overall, $3 \%$ for boys and $2 \%$ for girls) and western regions (3\% overall and for subsamples of boys and girls) come last in the secondary school attainment rates and there is no discernible difference between the two regions and across the subsamples at this level. Further, at postsecondary level, the central region has the highest overall attainment rate of 2 percent, 1.4 percent for boys and 2 percent for girls. The Eastern region has an overall postsecondary attainment rate of 0.7 percent, 1 percent for boys and 0.5 percent for girls. The northern region has an overall postsecondary attainment rate of 0.3 percent, 0.5 percent for boys and 0.01 percent for girls. The western region has an overall postsecondary attainment rate of 0.7 percent, 0.5 percent for boys and 0.8 percent for girls. It is noteworthy that the central region's school attainment rates for girls is higher than that of boys at all levels, indicating the success of government policy targeting girls education. On the other hand, the western region leads all others in the primary school attainment rates, across all subsamples, followed by the northern region and the east and central regions (Table 3). There is need for a greater government effort intended to uplift regions that lag behind.

Rural areas are associated with a higher primary school attainment rate of 21 percent compared to only 18 percent for the urban areas. The same picture can be observed for the subsamples of boys (19\% in rural compared to $15 \%$ in urban) and girls (22\% in rural compared to $20 \%$ in urban) (Table 3). On the other hand, the urban area is associated with a higher secondary and postsecondary attainment rates compared to the rural area. The urban area is associated with a secondary school overall attainment rate of 11 percent, 10 percent for boys, and $13 \%$ for girls compared to only 3 percent for the rural area across all subsamples. Further, the urban area is associated with a postsecondary school attainment rate of 3 percent across all subsamples compared to only 0.5 percent for the rural area across all subsamples. The prominence of the urban area across all subsamples may be attributed to the concentration of highly educated parents who are obviously richer, having a good household environment access to the good social amenities like schools and hospitals.

It is noteworthy that the fertility behavior of parents reveals interesting associations with the school attainment rates of their children (Table 3). The higher the fertility rate, the lower the school attainment rates at all levels of education but more so at secondary and postsecondary levels. Parents with only one child are associated with an overall secondary school attainment rate of 8 percent, 10 percent for boys, and 12 percent for girls compared to only $2 \%$ associated with their counterparts with at least five children. Further, parents with only one child are associated with an overall postsecondary school attainment rate of 2.4 percent, 3 percent for boys, and 3.4 percent for girls. This is compared to only 0.2 percent for the full sample, 0.3 percent for boys, and 0.1 percent for girls. At primary level, parents with only one child are associated with an overall school attainment rate of 19 percent, 21 percent for boys, and 29 percent for girls. This is compared to those with over five children with only 17 percent for the full sample and 19\% for both boys and girls (Table 3). Whereas high fertility rates are associated with high enrolments, they compromise the quality of the outcome by leading to lower child completion rates. Therefore, such efforts as increasing access to contraceptives by mothers may help to reduce fertility and increase school attainment rates.

Table 4. Determinants of school attainment 13-30 years (ordered probit analysis: Marginal effects)

\begin{tabular}{|c|c|c|c|c|c|c|c|c|c|}
\hline \multirow[b]{2}{*}{ Variable } & \multicolumn{3}{|c|}{ Primary school Attainment } & \multicolumn{3}{|c|}{ Secondary school attainment } & \multicolumn{3}{|c|}{ Post-secondary attainment } \\
\hline & Full sample & Boys & Girls & Full sample & Boys & Girls & $\begin{array}{c}\text { Full } \\
\text { sample }\end{array}$ & Boys & Girls \\
\hline Female & 0.0362 & -0.00778 & 0.0531 & -0.0284 & 0.0069 & -0.0519 & -0.00221 & 0.00078 & -0.0012 \\
\hline $\begin{array}{l}\text { Education: } \\
\text { Primary }\end{array}$ & $(1.67)^{*}$ & -0.31 & $(2.04)^{* *}$ & $(1.67)^{*}$ & -0.31 & $(2.05)^{* *}$ & -1.59 & -0.31 & -1.65 \\
\hline \multirow{2}{*}{ Secondary } & -0.2632 & -0.0845 & -0.4246 & 0.2295 & 0.0744 & 0.3905 & 0.0337 & 0.0101 & 0.0341 \\
\hline & $(7.80)^{* * *}$ & $(2.09)^{* *}$ & $(7.75)^{* * *}$ & $(8.37)^{* * *}$ & $(2.13)^{* *}$ & $(8.49)^{* * *}$ & $(4.48)^{* * *}$ & $(1.72)^{*}$ & $(3.02)^{* * *}$ \\
\hline Post-secondar & -0.4314 & -0.0569 & -0.749 & 0.3411 & 0.05 & 0.5483 & 0.0903 & 0.0066 & 0.2001 \\
\hline $\mathrm{y}$ & $(7.77)^{* * *}$ & -0.92 & $(13.69)^{* * *}$ & $(10.02)^{* * *}$ & -0.94 & $(22.82)^{* * *}$ & $(3.78)^{* * *}$ & -0.8 & $(3.43)^{* * *}$ \\
\hline Partner's: & -0.00898 & 0.0292 & -0.036 & 0.0084 & -0.0262 & 0.0352 & 0.00063 & -0.003 & 0.0007 \\
\hline Primary & -0.32 & -0.7 & -1.01 & -0.32 & -0.7 & -1.01 & -0.32 & -0.68 & -0.97 \\
\hline \multirow{2}{*}{ Secondary } & -0.1483 & -0.217 & -0.0819 & 0.1346 & 0.1854 & 0.0798 & 0.0138 & 0.0312 & 0.0021 \\
\hline & $(3.87)^{* * *}$ & $(3.75) * * *$ & -1.63 & $(3.98)^{* * *}$ & $(3.97)^{* * *}$ & $(1.64)^{*}$ & $(2.83)^{* * *}$ & $(2.55)^{* *}$ & -1.24 \\
\hline
\end{tabular}




\begin{tabular}{|c|c|c|c|c|c|c|c|c|c|}
\hline Post-secondar & -0.2445 & -0.4067 & -0.111 & 0.2127 & 0.3086 & 0.1073 & 0.0318 & 0.0981 & 0.0034 \\
\hline y & $(4.24)^{* * *}$ & $(4.77) * * *$ & -1.58 & $(4.60) * * *$ & $(6.16)^{* * *}$ & -1.6 & $(2.64) * * *$ & $(2.56)^{* *}$ & -1.09 \\
\hline \multirow{2}{*}{ Region: East } & -0.0288 & -0.049 & -0.0084 & 0.0267 & 0.0439 & 0.0082 & 0.00214 & 0.0054 & 0.0002 \\
\hline & -1.64 & -1.65 & -0.45 & -1.64 & -1.67 & -0.45 & -1.52 & -1.48 & -0.43 \\
\hline \multirow{2}{*}{ North } & 0.0375 & -0.0075 & 0.0785 & -0.0351 & 0.0068 & -0.0772 & -0.0025 & 0.0008 & -0.001 \\
\hline & $(2.31)^{* *}$ & -0.26 & $(5.37)^{* * *}$ & $(2.30)^{* *}$ & -0.26 & $(5.36)^{* * *}$ & $(2.34)^{* *}$ & -0.25 & $(3.11)^{* * *}$ \\
\hline \multirow{2}{*}{ West } & 0.01301 & 0.00976 & 0.0221 & -0.0121 & -0.0088 & -0.0218 & -0.0009 & -0.00096 & -0.0004 \\
\hline & -0.8 & -0.36 & -1.31 & -0.8 & -0.36 & -1.31 & -0.82 & -0.36 & -1.3 \\
\hline \multirow{2}{*}{ Urban } & -0.07753 & -0.11178 & -0.0635 & 0.0711 & 0.0979 & 0.0619 & 0.00643 & 0.0139 & 0.0016 \\
\hline & $(3.99)^{* * *}$ & $(3.41)^{* * *}$ & $(2.76)^{* * *}$ & $(4.04) * * *$ & $(3.49)^{* * *}$ & $(2.77)^{* * *}$ & $(3.17)^{* * *}$ & $(2.62)^{* * *}$ & $(1.98)^{*}$ \\
\hline \multirow{2}{*}{$\begin{array}{l}\text { Water source: } \\
\text { Borehole }\end{array}$} & -0.0623 & -0.011 & -0.1125 & 0.0574 & 0.00988 & 0.1095 & 0.0048 & 0.0011 & 0.003 \\
\hline & $(2.87)^{* * *}$ & -0.35 & $(3.70)^{* * *}$ & $(2.89)^{* * *}$ & -0.35 & $(3.73)^{* * *}$ & $(2.50)^{* *}$ & -0.35 & $(2.34)^{* *}$ \\
\hline \multirow{2}{*}{ Protected well } & -0.0455 & -0.0052 & -0.0806 & 0.0419 & 0.0047 & 0.0785 & 0.0035 & 0.0005 & 0.00208 \\
\hline & $(2.17)^{* *}$ & -0.17 & $(2.91)^{* * *}$ & $(2.19)^{* *}$ & -0.17 & $(2.93)^{* * *}$ & $(1.93)^{*}$ & -0.17 & $(2.02)^{* *}$ \\
\hline \multirow{2}{*}{$\begin{array}{l}\text { Unprotected } \\
\text { well }\end{array}$} & -0.0431 & -0.0121 & -0.0667 & 0.0399 & 0.0108 & 0.0652 & 0.00322 & 0.001 & 0.0016 \\
\hline & $(2.13)^{* *}$ & -0.4 & $(2.54)^{* *}$ & $(2.14)^{* *}$ & -0.4 & $(2.55)^{* *}$ & $(1.94)^{*}$ & -0.39 & $(1.90)^{*}$ \\
\hline \multirow{2}{*}{$\begin{array}{l}\text { Number } \\
\text { children: } 2\end{array}$} & 0.0242 & 0.0119 & 0.0276 & -0.0226 & -0.0108 & -0.0271 & -0.0016 & -0.0012 & -0.0005 \\
\hline & -1.41 & $(0.38$ & -1.59 & -1.4 & -0.38 & -1.59 & -1.47 & -0.39 & -1.6 \\
\hline \multirow{2}{*}{3} & 0.0411 & 0.03997 & 0.0307 & -0.0385 & -0.0363 & -0.0302 & -0.0026 & -0.0037 & -0.0005 \\
\hline & $(2.51)^{* *}$ & -1.39 & $(1.75)^{*}$ & $(2.49)^{* *}$ & -1.38 & $(1.75)^{*}$ & $(2.64)^{* * *}$ & -1.48 & $(1.76)^{*}$ \\
\hline \multirow{2}{*}{4} & 0.0416 & 0.0183 & 0.0374 & -0.03896 & -0.0165 & -0.037 & -0.0026 & -0.0018 & -0.0006 \\
\hline & $(2.37)^{* *}$ & -0.55 & $(2.06)^{* *}$ & $(2.35)^{* *}$ & -0.54 & $(2.05)^{* *}$ & $(2.52)^{* *}$ & -0.57 & $(2.03)^{* *}$ \\
\hline \multirow{2}{*}{5} & 0.0766673 & 0.105 & 0.0483 & -0.0711 & -0.0936 & -0.0473 & -0.0056 & -0.0114 & -0.001 \\
\hline & $(4.33)^{* * *}$ & $(3.43)^{* * *}$ & $(2.45)^{* *}$ & $(4.33)^{* * *}$ & $(3.46)^{* * *}$ & $(2.45)^{* *}$ & $(3.68)^{* * *}$ & $(2.83)^{* * *}$ & $(2.04)^{* *}$ \\
\hline $\mathrm{N}$ & 4223 & 1819 & 2404 & 4223 & 1819 & 2404 & 4223 & 1819 & 2404 \\
\hline $\begin{array}{l}\text { Pseudo } \\
\text { R-square }\end{array}$ & 0.2602 & 0.2101 & 0.4104 & 0.2602 & 0.2101 & 0.4104 & 0.2602 & 0.2101 & 0.4104 \\
\hline Log-likelihood & -1748.4 & -843.91 & -762.313 & -1748.4 & -843.91 & -762.31 & -1748.4 & -843.91 & -762.313 \\
\hline
\end{tabular}

Absolute value of $\mathrm{z}$ statistics in parentheses; * significant at $10 \%$; ** significant at $5 \%$; *** significant at $1 \%$; N.B Toilet type, religion, fathers occupation and female head are included in all regressions models presented in table 4 .

Table 4 present results from an ordered probit estimation relating child school attainment and parents' schooling together with other socioeconomic factors. The results indicate that parents' schooling at higher levels negatively influences primary school attainment of children irrespective of gender. The positive effect of parents' schooling on child education attainment is observed at higher levels of child schooling (or secondary and postsecondary).

Mothers with secondary and postsecondary education reduce the probability of child primary school attainment by 26 percent and 43 percent respectively, compared to their counterparts with no education at all. Considering the girls' subsample, the results show that mothers' education effect is even more assertive. That is, mothers with secondary and postsecondary education reduce the probability of girl primary school attainment by 43 percent and 75 percent respectively, compared to their counterparts with no education at all. For boys, mothers' education is feeble. It is only secondary education that is significant in reducing boys' primary school attainment and yet with a relatively smaller probability of 8 percent. On the other hand, mothers' primary schooling increases the probability of child primary school attainment by 4 percent for the full sample and 5 percent for girls compared to their counterparts with no education at all. In addition, our results show that fathers with secondary and postsecondary education, compared to those with no education, reduce the probability of child primary school attainment by 15-24 percent for the full sample and 22-41 percent for the subsample of boys. For girls, fathers' education is 
completely insignificant in influencing their primary education attainment. Mothers and fathers inclination towards girls and boys school attainment, respectively, is also evident at this level of analysis. It is clear from our results that parent's education at lower levels favors the attainment of lower education by their children but disfavors the attainment of higher education by their children. Sincere we employed an ordered probit model where we isolated cohorts of children into those who completed and stopped at primary, secondary, and postsecondary levels, these findings are as expected and therefore not surprising.

Considering child secondary school attainment, the results show that mothers' primary education reduces the probability of child secondary school attainment by 3 percent for the full sample and $5 \%$ for the subsample of girls compared to those with no education at all. However, mothers' secondary and postsecondary education increases the probability of child secondary school attainment by 23-34 percent for the full sample and 39-55 percent for the subsample of girls compared to those with no education. Again, for boys, it is only mothers' secondary education that is significant and yet with a relatively smaller probability of 7 percent. Also, the results show that fathers' secondary and postsecondary education, compared to those with no education, increases the probability of child secondary school attainment 14-21 percent for the full sample and 19-31 percent for the subsample of boys. For girl, fathers' education is weak; it is only secondary education that increases the probability of child secondary school attainment and moreover with a relatively smaller probability of 8 percent. Again, mothers and fathers inclination towards girls and boys school attainment is also pronounced at this level of analysis. It is clear that parents' education at higher levels favors higher education attainment by their children and disfavor lower education attainment by their children. In this ordered probit setting, the findings are as expected and hence not surprising.

Furthermore, considering child postsecondary attainment, mothers' secondary and postsecondary education, compared to those with no education, increases the probability of child postsecondary school attainment by 4-9 percent for the full sample and 3-20 percent for the subsample of girls.

Again, the impact of mothers' education on the boys' postsecondary education attainment is very weak. It is only secondary education of the mother that is weakly significant and with a relatively smaller probability of 1 percent. The findings indicate that fathers' secondary and postsecondary education, compared to those with no education, increases the probability of child postsecondary school attainment by 1.4-3.2 percent for the full sample and 3-10 percent for the subsample of boys. Fathers' education is completely insignificant in influencing postsecondary school attainment for the subsample of girls. This can probably be attributed to cultural beliefs where parents, especially fathers, attach lower value to the education of girls compared to boys. Additionally, there are more women than men in the various movements and efforts that advocate for girls child rights to equal education. The quantitative findings from the ordered probit model find support from the descriptive findings in Table 2 . The significant impact of parents' education on child schooling outcomes finds support in the previous literature (Glick et al., 2000; Brown et al., 2002; Sackey et al., 2007; Mani et al., 2009 and Lam et al., 1999).

A number of policy lessons may be derived from this analysis. The first is that parents' education reduce the probability of child schooling attainment at lower levels of child schooling (primary) and increases it at secondary education and beyond. The second is that, whereas parents' schooling is associated with higher overall child education attainment rates, there is a differential impact of parents' education attainment on boys' and girls' schooling attainment rates. The results point out that fathers' and mothers' education tends to be inclined towards boys and girls education attainment respectively. It is noteworthy that apart from parents' education, a number of other factors are articulated in our findings as significantly associated with child schooling attainment outcome. These include; regional differences, location (urban/rural), social environment, household environment, and fertility behavior of households. These factors are statistically significant at conventional levels and are fully supported by the descriptive findings in Table 2 .

\section{Conclusions}

This paper presented an analysis of the determinants of school enrolment and attainment rates in Uganda by considering the gender perspective. We used data drawn from UDHS (2006) survey and employed maximum likelihood binary and ordered probit models in our estimation. Whereas the results show that improvements in parents' education promote the school enrolment and attainment rates of both boys and girls, it is not without inclination. The findings indicate that fathers' education significantly favors boys' schooling and yet mothers' education significantly favors girls' schooling. This suggests that there are differences in parents' preferences for schooling of boys and girls. It is also found that the higher the parents' education (secondary and postsecondary levels) the more favorable are the child schooling and late child birth. The number of child in a household increases school enrolment rates but reduces school attainment rates especially at higher levels of child schooling. In 
addition, household environment, represented by the water source of the household, significantly affects the girls' education but not the boys'. Also, community environment, represented by the urban location, significantly increases child school attainment rates particular at secondary and postsecondary levels, compared to the rural area. The northern region stands out in reducing schooling attainment rates especially at higher levels compared to the central region. Policies such as subsidized childcare that reduce the opportunity cost of girls' time in the home may therefore increase their ability to get an education.

Therefore, for more favorable schooling outcomes for the future generation, the government should strengthen policies aimed at educating boys and girls beyond secondary level. The government free secondary education program is a good start but not sufficient and hence requires further support. Also the government should encourage the modern use of contraceptives, by making them more accessible and cheaper, which may help to reduce fertility and increase child school attainment at higher levels. Government can also undertake a program that campaigns for a clean household environment and also earmark finances meant for providing clean water and other sanitary facilities at the household level across all regions and locations. Regions in greater need should be supported by the government through facilitating qualified teachers and providing scholastic materials to these areas. The autonomy of mothers in taking key decisions in the household that influence child quality need to be strengthened through community sensitization campaigns or government legislation. The fact that children whose mothers are independent were more likely to be enrolled into school suggests a great need for promoting the autonomy of mothers.

\section{References}

Alderman, H., Behrman, J. R., \& Menon, R. (2000). Child Health and School Enrollment: A Longitudinal Analysis. Journal of Human Resources, 56, 185-205.

Becker, G. S. (1991). A Treatise on the Family (2nd ed.). Cambridge: Harvard University Press.

Behrman, J. R., \& Wolfe, B. L. (1984). The Socioeconomic Impact of Schooling in a Developing Economy. Review of Economics and Statistics, 66(2), 296-303.

Behrman, J. R., \& Wolfe, B. L. (1987). Investment in Schooling in Two Generations in Pre-Revolutionary Nicaragua: The Roles of Family Background and School Supply. Journal of Development Economics, 27, 395-419.

Birdsall, N. (1985). Public Inputs and Child Schooling in Brazil. Journal of Development Economics, 18(1), 67-86

Brown, P. H., \& Park, A. (2002). Education and Poverty in Rural China. Economics of Education Review, 21, 523-541

Bruce, C., \& Anderson, C. (2004). The Impact of Family Background on Educational Attainment in Canada. Department of Economics, Discussion Paper 2004-19. University of Calgary, Canada

Desai, S., \& Alva, S. (1998). Maternal Education and Child Health: Is there a Strong Causal Relationship?" Demography, 35(1), 71-81.

Frosta, M. B., Forsteb, R., \& Haas, D. W. (2005). Maternal Education and Child Nutritional Status in Bolivia: Finding the Links. Social Science \& Medicine, 60, 395-407

Glewwe, P., Jacoby, H. G., \& King, E. M. (2001). Early childhood nutrition and academic achievement: A Longitudinal Analysis. Journal of Public Economics, 81, 345-368.

Glick, P., \& Sahn, D. E. (2000). Schooling of girls and boys in a West African Country: The Effects of parental education, Income and household Structure. Economics of Education Review, 19, 63-87

Grossman, M. (1987). On the concept of health capital and the demand for health. Journal of Political Economy, $80(2), 223-255$

King, E. M., \& Bellew, R. (1988). Education Policy and Schooling Levels in Pern. Washington, D.C.: Processed. The World Bank, 1988.

Lam, D., \& Duryea, S. (1999). Effects of schooling on fertility, labour supply, and investments in children, with evidence from Brazil. Journal of Human Resources, 34(1), 160-190.

Mani, S., Strauss, J., \& Hoddinott, J. (2009). Determinants of Schooling Outcomes -Empirical Evidence from Rural Ethiopia. Discussion Paper No: 2009-03. Department of Economics Fordham University.

Orazem, P. F., \& King, E. M. (2008). Schooling in Developing Countries: The Roles of Supply, Demand and Government Policy. In T. P. Schultz, \& J. Strauss (Eds.), Handbook of Development Economics, 4. 
Parish, W. L., \& Willis, R. J. (1993). Daughters, Education, and Family Budgets: Taiwan Experiences. Journal of Human Resource, 28(4), 863-898.

Republic of Uganda. (2008). Revised Education Sector Strategic Plan 2007-2015; Ministry of Education and Sports, Kampala Uganda.

Sackey, H. A. (2007). The Determinants of School Attendance and Attainment in Ghana: A Gender Perspective. AERC Research Paper 173 African Economic Research Consortiums, Nairobi December 2007.

Schultz, T. P. (1988). Educational Investments and Returns, In H. Chenery, \& T. N. Srinivasan (Eds.), Handbook of Development Economics (Vol. 1). Amsterdam: North Holland Press.

Schultz, T. P. (1993). Returns to Women's Education. In E. M. King, \& M. A. Hill (Eds.), Women's Education in Developing Countries: Barriers, Benefits and Policies (pp. 51-99). Baltimore and London: The Johns Hopkins University Press for the World Bank.

Strauss, J., \& Thomas, D. (1995). Human Resources: Empirical Modeling of Household and Family Decisions. In J. R. Behrman, \& T.N. Srinivasan (Eds.), Handbook of Development Economics (Vol. 3).

The United Nations. (2008). United Nations Millennium Declaration, 18 September 2000

Uganda Bureau of Statistics (UBOS) and Macro International Inc. (2007). Uganda Demographic and Health Survey 2006. Calverton, Maryland, USA: UBOS and Macro International Inc.

\section{Notes}

Note 1. These are average percentages generated from the author's own analysis of the DHS 2006 data set.

Note 2. www.gender.mak.ac.ug/index.php?

\section{Copyrights}

Copyright for this article is retained by the author(s), with first publication rights granted to the journal.

This is an open-access article distributed under the terms and conditions of the Creative Commons Attribution license (http://creativecommons.org/licenses/by/3.0/). 